\title{
DELAYED TRAUMATIC RUPTURE OF AORTA
}

\author{
BY \\ D. A. L. BOWEN AND R. D. TEARE \\ From the Department of Forensic Medicine, St. George's Hospital, London, S.W.I
}

(RECEIVED FOR PUBLICATION AUGUST 23, 1961)

Those engaged in the treatment of road traffic accidents are increasingly aware of the effects of blunt force injury to the chest, which may result in a variety of intrathoracic damage to the heart and great vessels.

Traumatic aortic rupture is a rare but wellrecognized entity, all too often diagnosed at necropsy. Teare (1951) showed it to be the cause of death in eight of 28 victims of an aircraft disaster, the result of acute flexion of the body over a safety belt. Strassmann (1947) recorded 72 cases from the Office of the Chief Medical Examiner, New York City ; and Parmley, Mattingly, Manion, and Jahnke (1958) 171 cases out of 275 in which aortic damage was combined with cardiac injury. Only $20 \%$ survived more than 30 minutes following injury.

Traumatic aneurysm is a much rarer injury, and until the last decade cases had only been reported by Shennan (1929), Rindfleisch (1893), Samson (1931), Kleinsasser (1943), Forbes (1944), Leonard (1945), Stryker (1948), Bradford and Johnston (1950), and Rice and Wittstruck (1951). Hollingsworth, Johnston, and McCooey (1952) reported three cases and reviewed previous cases, stating that none had survived more than one year and all had been diagnosed at necropsy. Since then Goyette, Blake, Forsee, and Swan (1954), Jay and French (1954), Ware, Adler, and Lyter (1955), Storey, Nardi, and Sewell (1956), Gerbode, Braimbridge, Osborn, Hood, and French (1957), Ellis (1959), and Malm and Deterling (1960) have focused more attention on the subject. Traumatic aneurysm is closely related to traumatic rupture, as its formation depends on the tensile strength of the adventitial tissues to prevent complete rupture at the time of injury, leading to survival for sufficient time to cause an aneurysm to develop. In Strassmann's series, 64 had ruptured all layers of the aortic wall resulting in death within one hour of injury in 59 instances.

Recently Spencer, Guerin, Blake, and Bahnson (1961) reported eight instances of traumatic aneurysm in a series of 15 cases of aortic " rupture" and a total of 60 cases in the English literature to date ; in 28 of the 43 reviewed in some detail, aneurysms had been successfully excised.

The present two cases are of interest, as they were undiagnosed during life. One survived injury for five hours and the other for 13 days; there was no serious damage to the thoracic cage in the second case.

\section{CASE RePORTS}

CASE 1.-On May 5, 1961, at 11 p.m. a pedestrian was seen wandering across the road, head down, and was struck by a passing motor vehicle and thrown into the air, landing on the road surface. On admission to hospital at 11.30 p.m. he was found to have a lacerated wound and bruising above the right eye. abrasions beneath the chin from one side of the jaw to the other, and a fracture of both bones of both lower legs nine inches above the heel with bruising and abrasions on both shins. After resuscitation he was taken to the theatre and suddenly collapsed and died during the induction of anaesthesia at 3.15 a.m. on May 6, 1961.

Post-mortem examination showed the deceased to be a powerfully built man with superficial abrasions and bruising on the lower legs and scalp. Apart from the fracture of the legs, the second to seventh ribs on the right side of the chest were fractured posteriorly and the left third to sixth ribs were also fractured in two places. There was a fracture of the right pubic ramus.

A surgical incision had been made into the pericardial sac for the purposes of heart massage and about half a pint of blood was present in the right chest space, both lungs being partially collapsed, especially the right, which was bruised and lacerated. The mediastinal tissues were distended with blood.

Immediately distal to the origin of the left subclavian artery, a tear was seen almost encircling the aorta, leaving only a small cuff of intact wall on its anterior aspect. At its margin adherent thrombus protruded into the lumen and blended with blood clot that had diffused into and distended the adventitial coat for several inches on either side of the aorta without producing any true dissection (Fig. 1).

The liver showed numerous lacerations and the mesentery of the caecum had been torn away over 


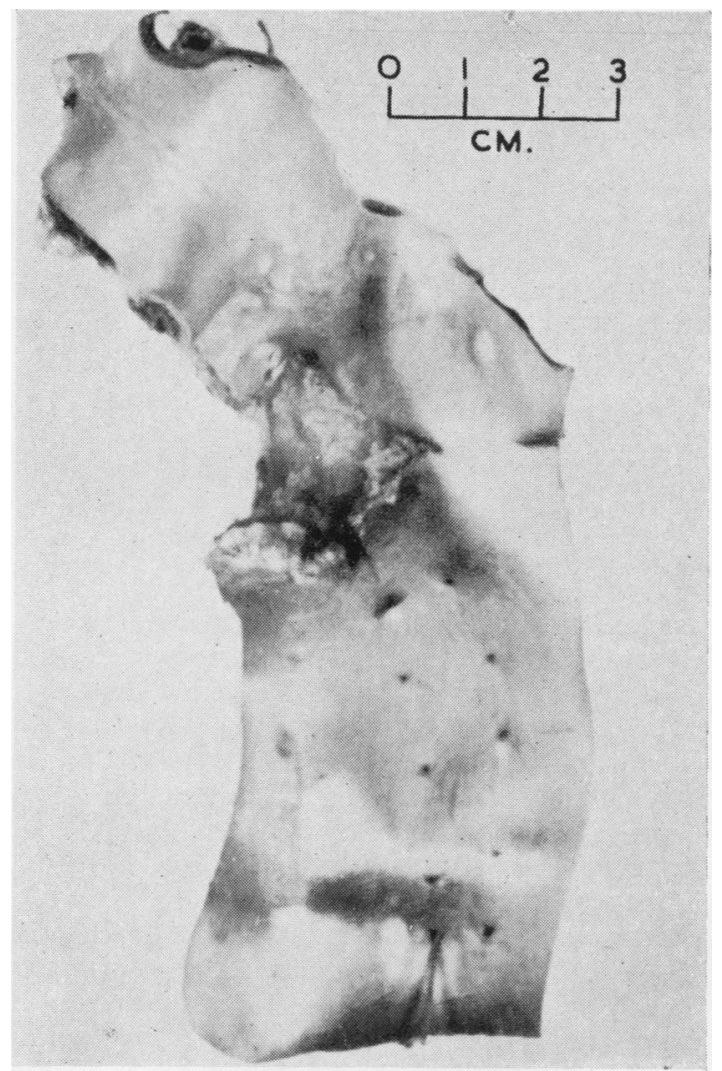

FIG. 1.-Case 1. A tear almost encircles the aorta, leaving a small cuff of intact wall on the anterior aspect.

its peritoneal reflection with bruising in this area and around the kidneys.

There was no significant natural disease.

CASE 2.-On May 7, 1960, shortly before midnight a motor-cyclist, aged 21 years, was following a friend similarly mounted when their machines collided. The victim of the present report was thrown forwards from his machine and landed on the road, possibly striking a bollard. On admission to hospital he was very shocked and had sustained a fracture of the left iliac crest and right pubic bone. A chest radiograph was not taken, as there was no apparent indication for it, and after resuscitation with blood transfusion a Lottes pin was inserted into the tibia. Over the next few days the patient's general condition improved. An area of bruising was, however, recorded along the left loin and chest after the second day of admission, and also at this time haematuria and oliguria were noted. Blood urea was found to be $225 \mathrm{mg} . / 100 \mathrm{ml}$. Sodium, potassium, and chloride levels were normal. The blood urea reached $250 \mathrm{mg}$./ $100 \mathrm{ml}$. on the fifth day following admission, but the following day diuresis of 2.51 . occurred. Thereafter the urea level fell and was recorded as $81 \mathrm{mg}$. !
$100 \mathrm{ml}$. on the eighth day. His general condition continued to improve and was excellent when, in the early hours of May 20, 13 days after admission, he hiccupped, became pulseless, and died.

Post-mortem examination showed the deceased to be a well-built and sparely nourished young man with bruising of the superficial tissues along the left side of the chest and upper abdomen. Scattered healing lacerations and fading bruising were seen on the left leg, ankle, and forearm; the body was very pale. There was no arachnodactyly. Internally both bones of the left leg were fractured eight inches above the heel, and a surgical pin had been inserted into the tibia satisfactorily. An oblique fracture ran along the right pubic bone and a depressed fracture of the left ilium was evident with adjacent bruising.

The brain (52 oz.) showed no evidence of injury. and the cerebral arteries were healthy. Intense pallor of the white matter was evident.

The pericardial sac was intact. The heart weighed $11 \mathrm{oz}$. and was devoid of blood. There was no valvular disease, and apart from the aneurysm the aorta appeared healthy with no evidence of coarctation. The coronary arteries were free of disease and quite patent, and the myocardium was normal. On the posterior and inferior aspect of the aorta a saccular aneurysm, one inch in diameter, was present at a point immediately distal to the left subclavian artery, at the site of the ligamentum arteriosum. A perforation was evident at the apex of the sac, and six to seven pints of fluid blood and clot were present in the left pleural cavity. The underlying lung showed collapse. On opening the aorta a tear was evident across the intima, involving the media for a distance of one inch by half an inch. The adventitial coat was thickened and lined by blood clot, except at the point of rupture. It appeared that an aneurysmal sac had formed following a tear of the aortic wall. and this had eventually burst to flood the pleural space with blood (Fig. 2). The right lung was congested and the air passages healthy.

No abnormality was found in the alimentary system.

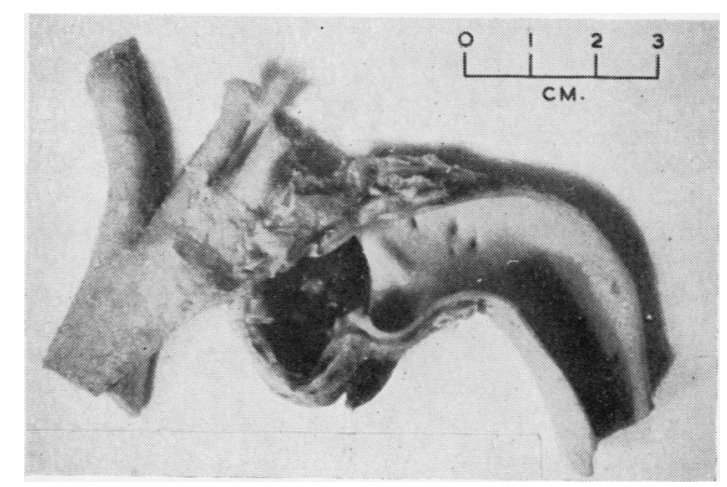

Fig. 2.-Case 2. A burst aneurysmal sac, formed after an aortic tear. 
Neither kidney ( $7 \mathrm{oz}$.) showed evidence of injury and the ureters were healthy, but bruising was seen in the tissues around the bladder, which was intact.

The spleen weighed $7 \mathrm{oz}$. and was intact.

Microscopical examination showed no evidence of medial degeneration or syphilis in the ascending aorta; the aneurysmal sac was composed of granulation tissue.

\section{Discussion}

The aorta is readily susceptible to the effects of deceleration as it tends to decelerate slowly, behaving like a solid viscus on account of its column of blood. Hass (1944) has emphasized the stresses placed on unevenly decelerating organs in the following words, "Whenever one part of the body is decelerated at a rate different from another, the connection between the parts is placed under stress proportional to the rate of deceleration." The result, as far as the aorta is concerned, is to subject it to stretching or torsion, especially at its points of fixation, which would be the junction of unequal rates of deceleration.

Aortic tears may occur in the ascending aorta above the aortic cusps, in the aorta at the site of the ligamentum arteriosum (isthmus), and very occasionally between the isthmus and the diaphragm. The most common point of rupture is the isthmus, accounting for at least $60 \%$ of traumatic aortic ruptures. Strassmann pointed out that the arch is a relatively fixed structure whereas the distal portion is relatively mobile. Marshall (1958) considered the most usual site of rupture to be between the attachment of the ligamentum arteriosum and the origin of the first intercostal artery as a strain was imposed on the segment of the aorta at this point. Above it the vessel was held by the neck structures and below by pleura and intercostal arteries. He mentioned two other factors: a calcified plaque at the point of attachment of the ligamentum arteriosum and also displacement of the aorta against the spine following tension on the hilum of the left lung.

A more ingenious theory was that of Rice and Wittstruck (Fig. 3), who envisaged the central portion of the descending aorta snapping forward by the momentum of the decelerating force of the mass of blood within the vessel. As the upper part of the aorta is fixed by the great vessels and the ligamentum arteriosum, it would decelerate at the same rate as the whole body whereas, because of its less rigid fixation, the descending aorta decelerates at a different rate, the difference constituting a force concentrated at the point of maximum fixation. If this were so, one might expect fairly constant intercostal bruising and

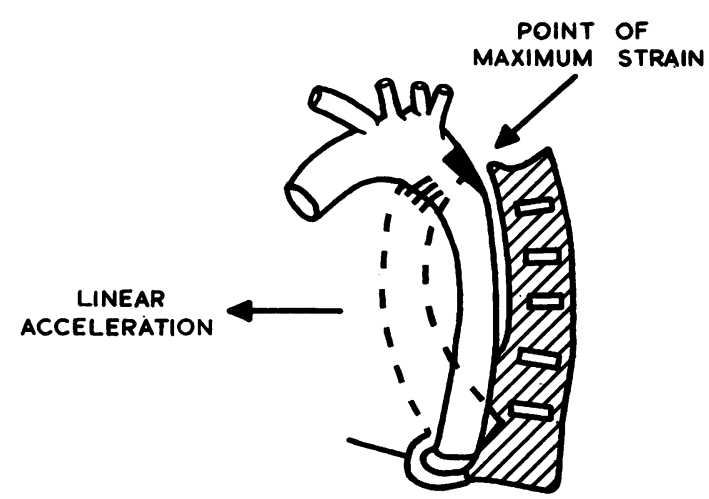

FIG. 3.-Diagrammatic representation of the mechanism of laceration of the healthy aorta by indirect violence. [By courtesy of the authors (Rice and Wittstruck, 1951).]

laceration of the intercostal arteries, findings absent in both patients. Those factors affecting natural dissection may also operate in regard to traumatic rupture of the ascending aorta. The valve commissures may exert a rocking force and pull on the aortic wall as the valves are closed in diastole by the column of blood above it, the aorta being also firmly attached to the underlying pulmonary artery.

Cammack, Rapport, Paul, and Baird (1959) have investigated the mechanical principles and underlying stresses imposed upon the aorta in deceleration chest injuries. It appears that severe torsion, stress, and bending forces may all play a part in producing the greatest strain on the point where the aorta is most rigidly fixed to the chest wall at the isthmus. They also report nine cases in which rupture followed horizontal deceleration, four surviving from one and a half to 14 days.

It is possible that sudden compression of the chest may find the heart held in between the inflated lungs. The increasing likelihood of aortic damage in present-day traffic conditions and advances in arterial surgery make the diagnosis of traumatic aneurysm of more than academic interest. The possibility of a traumatic origin of aneurysms of the descending aorta in young persons should be considered, and inquiry made as to previous chest trauma. In elderly persons the aortic wall would be less likely to withstand trauma owing to degenerative change (medionecrosis). In addition, modern resuscitative measures can successfully deal with blood loss and skeletal injury, as in Case 2 , so that survival following decelerating injuries may allow the development of aortic aneurysms. It is important to bear in mind the possibility of aortic rupture in 
any chest injury, as in the early stage repair is feasible and aneurysmal resection may be possible later on. This is particularly important in the first few weeks following injury, as Spencer et al. (1961) found no sudden deaths following ruptured traumatic aneurysm more than a few months old. In seven out of eight patients aneurysms were successfully excised, but there was only one survival in seven cases of aortic rupture, due to the difficulty of diagnosis. Using atrial-femoral bypass, resection of the descending aorta involves a mortality of $19 \%$ compared with 27 to $50 \%$ using hypothermia or external shunts (DeBakey, Cooley, Crawford, and Morris, 1958).

The diagnosis depends on observation of any symptoms of mediastinal compression and serial postero-anterior radiographs. The latter may reveal progressive mediastinal widening due to extravasation of blood from the aortic leak, and Wyman (1953) described increased layering around the aortic shadow. So radiographic screening is also advisable and aortography can reveal the site of rupture.

\section{Summary AND Conclusions}

A report is presented on two patients who sustained delayed traumatic rupture of the thoracic aorta. The first was a pedestrian, aged 45 years, who died five hours after being struck by a motor vehicle, and the second a 21-year-old motor-cyclist who survived multiple skeletal injuries and haemorrhage, dying unexpectedly 13 days later from a ruptured traumatic aneurysm of the aorta.

Serial radiographs of the mediastinum are advisable whenever a concealed chest injury may have occurred and aortography may be carried out, if necessary, to confirm the diagnosis, since advances in vascular surgery have made possible aneurysmal excision and successful repair. Previous chest trauma should be suspected in a person of any age presenting with an aneurysm at this site, especially when natural disease is absent, as present-day traffic conditions may be an increasingly common source of such pathology.

We should like to thank the Department of Orthopaedic Surgery, St. George's Hospital, for access to the case records of the second patient, and Miss $\mathrm{J}$. Slatford for the photographs.

\section{ADDENDUM}

Since this paper was submitted for publication, Dr. W. S. Killpack, of King Edward VII Hospital, Ealing, has kindly given us details of a further case of delayed aortic rupture in a 16-yearold motor-cyclist who sustained multiple limb fractures with severe shock, and collapsed and died suddenly nine days afterwards.

Dr. Killpack carried out a post-mortem examination and found a complete tear of the thoracic aorta immediately distal to the origin of the great vessels, the adventitial tissues being grossly infiltrated and thickened with blood clot for a distance of three inches distal to the tear.

This case provides an interesting comparison with the two reported here in that, although no aneurysm had developed, probably due to a complete aortic tear, the resulting initial haemorrhage had provided an effective splint, so delaying the final rupture. There were no clinical signs to suggest a chest injury and a chest radiograph on admission to hospital showed no abnormality.

\section{REFERENCES}

Bradford, B., and Johnston, F. L. (1950). Surgery, 28, 893.

Cammack, K., Ranport, R. L., Paul, J., and Baird, W. C. (1959). A.M.A. Arch. Surg., 79, 244.

DeBakey, M. E., Cooley, D. A . Crawford, E. S., and Morris, G. C. (1958). J. thorac. Surg., 36, 393.

Ellis, F. (1959). Brit. J. Surg., 46, 495.

Forbes, G. (1944). B-it. med. J., 2, 400

Gerbode, F., Braimbridge, M., Osborn, J. J., Hood, M., and French, S. (1957). Surgery, 42, 975.

Goyette, E. M., Blake, H. A., Forsee, J. H., and Swan, H. (1954). Circulation, 10, 824.

Hass, G. M. (1944). J. Aviat. Med., 15, 77.

Hollingsworth, R. K.. Johnston, W. W., and McCooey, J. F. (1952). J. thorac. Surg., 24, 325.

Jay, J. B., and French, S. W. (1954). A.M.A. Arch. Surg., 68, 657.

Kleinsasser, L. J. (1943). Ann. Surg., 118, 1071.

Leonard, D. W. (1945). Amer. J. Surg., 69, 344.

Malm, J. R, and D terling R. A. (19-0). J. thorac. Surg., 40, 271.

Marshall, T. K. (1958). J. clin. Path., 11, 36.

Parmley, L. F., Mattingly, T. W., Manion, W. C., and Jahnke, E. J. (1958). Circulation, 17, 1086.

Rice, W. G., and Wittstruck, J. P. (1951). J. Amer. med. Ass., 147, 915.

Rindfleisch, E. (1893). Virchows Arch. path. Anat., 131, 374.

Samson, P. C. (1931). Ann. intern. Med., 5, 117.

Shennan, T. (1929). J. Path. Bact., 32, 795.

Spencer, F. C., Guerin, P. F., Blake, H. A., and Bahnson, H. T. (1961). J. thorac. cardiovasc. Surg., 41, 1.

Storey, C. F., Nardi, G. L., and Sewell, W. H. (1956). Ann. Surg., $144,69$.

Strassmann, G. (1947). Amer. Heart J., 33, 508.

Stryker, W. A. (1948), Amer. J. clin. Path., 18, 152.

Teare, R. D. (1951). Brit. med. J., 2, 707.

Ware, P. F., Adler, R. H., and Lyter, C. S. (1955). U.S. armed Forces med. J., 6, 1674

Wyman, A. C. (1953). A.M.A. Arch. Surg., 66, 656. 